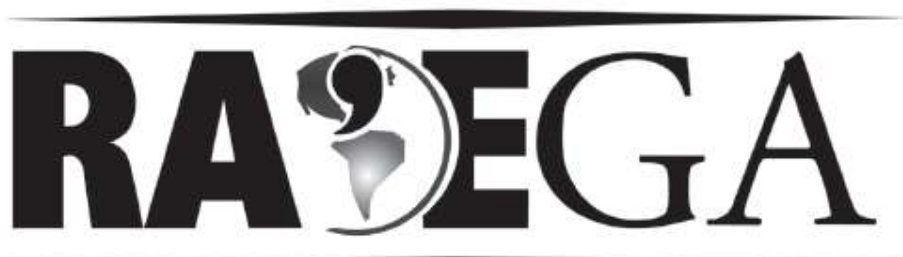

O ESPAÇO GEOGRÁFICO EM ANÁLISE

\title{
ESTUDO DA COBERTURA VEGETAL/USO DA TERRA NOS ANOS DE 1987 E 2007 NO NÚCLEO DE DEGRADAÇÃO/DESERTIFICAÇÃO DE SÃO RAIMUNDO NONATO - PIAUÍ.
}

\section{STUDY OF THE VEGETATION COVERAGE/LAND USE DURING THE YEARS OF 1987 AND 2007 IN THE NUCLEUS OF DEGRADATION/DESERTIFICATION OF SÃO RAIMUNDO NONATO - PIAUÍ.}

\author{
Cláudia Maria Sabóia de Aquino ${ }^{1}$ \\ José Antonio Pacheco de Almeida ${ }^{2}$ \\ José Gerardo Beserra de Oliveira ${ }^{3}$
}

\section{Resumo}

A cobertura vegetal é um componente de grande relevância para o equilíbrio ambiental, uma vez que assegura a proteção dos solos contra a erosão hídrica. Esta é recomendada pela ONU como um indicador para fins de avaliação do processo de desertificação. Considerando que aproximadamente $45,3 \%$ do estado do Piauí apresentam suscetibilidade a desertificação, este trabalho objetivou analisar de forma espaço-temporal, com o emprego de técnicas de

\footnotetext{
${ }^{1}$ Profa Dra Universidade Federal do Piauí (UFPI). Departamento de Geografia. Teresina, Piauí, Brasil. e-mail: cmsaboia@gmail.com

${ }^{2}$ Prof. Dr. Universidade Federal de Sergipe (UFS). Núcleo de Geologia. Aracaju, Sergipe, Brasil. e-mail: pachecoalmeida@ig.com.br

${ }^{3}$ Prof. Dr. Universidade Federal do Ceará (UFC). Departamento de Biologia. Fortaleza, Ceará, Brasil. e-mail: jgboliv@gmail.com
} 
sensoriamento remoto (detecção de mudanças), a dinâmica da cobertura vegetal/uso da terra no Núcleo de São Raimundo Nonato, para fins de avaliar a degradação/desertificação. Os resultados mostraram que houve decréscimo significativo da classe de cobertura vegetal/uso da terra do tipo agricultura+solos exposto. Esta decresceu de 31,1\% em 1987 para 26,8\% em 2007. Já na classe caatinga arbustiva densa, constatou-se incremento de $24,9 \%$ para $39,3 \%$. Os resultados sugerem o aumento da proteção oferecida pela cobertura vegetal que em 1987 era de $15,7 \%$ passou para $17,5 \%$ em 2007, com consequente diminuição do processo de degradação/desertificação na área de estudo.

Palavras-chaves: Sensoriamento Remoto; Cobertura Vegetal; Uso da Terra; NDVI; Desertificação.

\section{Abstract}

The vegetation coverage is a component of great relevance for the environmental equilibrium, since it guarantees the protection of the soils against hydric erosion. This is recommended by $\mathrm{UN}$ as an indicator for the evaluation process of desertification. Considering that approximately $45,3 \%$ of the state of Piauí presents susceptibility to desertification, this work has the objective of analysing the spatial-temporal form from the standpoint of employment of remote sensoring techniques (change detection) for the dynamics of vegetation coverage/land use in the Núcleo de São Raimundo Nonato, in order to evaluate the degradation/desertification. The results show that there was a significant decrease of the class of vegetation coverage/land use of the agricultural+exposed soils types. This decreased from $31,1 \%$ in 1987 to $26,8 \%$ in 2007. In the shruby and dense caatinga, it was noticed an increase from $24,9 \%$ to $39,3 \%$. The results suggest an increase in the protection offered by the vegetation coverage that was equal to $15,7 \%$ in 1987 , and changed to $17,5 \%$ in 2007 , as a resulting decrease of the degradation/desertification process of the studied area.

Keywords: Remote Sensing; Vegetation Cover; Land Use; NDVI; Desertification.

\section{Introdução}

Nos últimos dois séculos é notório o incremento dos danos causados pela sociedade urbano-industrial ao ambiente. As agressões podem ser exemplificadas através de práticas de desmatamento, queimadas, superpastoreio, etc. Estas práticas culminam com o comprometimento dos recursos naturais, solo, ar, fauna, recursos hídricos, perda e/ou redução da 
diversidade biológica e ainda, da cobertura vegetal, resultando no empobrecimento dos ecossistemas, especialmente os áridos, semiáridos e os subúmidos secos, com 0 consequente desencadeamento de áreas degradadas/desertificadas.

Fenômeno como Dust Bowl que ocasionou intensa degradação de solos secos de alta erodibilidade no meio oeste americano, nos anos de 1930, e a intensa seca na região do Sahel na África no período compreendido entre 1967-1970 inauguraram as preocupações relacionadas à desertificação e aos impactos sociais e econômicos resultantes deste processo nas regiões áridas e semiáridas do globo, inserindo a temática da desertificação na agenda política internacional.

Esses dois eventos despertaram 0 interesse pela temática da desertificação nos meios acadêmicos e políticos, inserindo definitivamente 0 tema na agenda política internacional (Brasil, 2004).

Durante a realização da Conferência de Estocolmo em 1972, considerando a gravidade das conseqüências da desertificação, decidiu-se na oportunidade pela realização da I Conferência das Nações Unidas sobre Desertificação (UNCOD) realizada em 1977 em Nairóbi, no Quênia. Na ocasião, a desertificação foi considerada como um problema de primeira magnitude, tendo sido definida como:

O empobrecimento dos ecossistemas áridos, semiáridos e alguns subúmidos pelo impacto das atividades do homem. A desertificação é o resultado do abuso da terra (Rhodes, 1992).

O não estabelecimento de um indicador para identificação das áreas suscetíveis a desertificação, combinado a inexistência de limites de aridez e, ainda, a não consideração dos aspectos climáticos na definição resultaram, em 1991, na elaboração de uma nova definição para o fenômeno da desertificação.

Segundo MMA (2008) os resultados alcançados a partir da realização da Conferência de Nairóbi foram mais do que modestos, fato que levou os países com problemas de desertificação, especialmente os da África, a elaborarem 
uma Convenção sobre desertificação. Esta Convenção foi realizada durante a Conferência das Nações Unidas sobre Meio Ambiente e Desenvolvimento (ECO-92). Esta Convenção representou um marco de inflexão nas discussões, posto ter definido o alcance do termo desertificação e o critério para identificação das áreas sujeitas a este processo. $\mathrm{Na}$ ocasião, desertificação foi definida como: "A degradação da terra nas zonas áridas, semiáridas e subúmidas secas resultante de vários fatores, incluindo as variações climáticas e as atividades humanas" (BRASIL, 1996, p. 9).

Por degradação da terra entende-se a redução ou perda, nas zonas áridas, semiáridas e subúmidas secas, da produtividade biológica ou econômica das terras agrícolas de sequeiro, das terras agrícolas irrigadas, das pastagens naturais, das pastagens semeadas, das florestas e das matas nativas devido aos sistemas de utilização da terra ou a um processo natural (secas) ou combinação de processos, incluindo os que resultam da atividade do homem e das suas formas de ocupação do território, tais como:

I. a erosão do solo causada pelo vento e/ou pela água;

II. a deterioração das propriedades físicas, químicas e biológicas ou econômicas do solo, e

III. a destruição da vegetação por períodos prolongados, com consequente redução da qualidade de vida das populações afetadas (BRASIL, 1996)

A Convenção das Nações Unidas de Combate à Desertificação considera como zonas áridas, semiáridas e subúmidas secas todas as áreas com exceção das polares e das subpolares - com Índice de Aridez (IA) entre 0,05 e 0,65, que é estimado pelo quociente entre a precipitação média anual (P) e a evapotranspiração potencial total anual (ETP). Os tipos de clima com suas respectivas amplitudes de aridez são apresentados no Tabela 1. 
Tabela 1 - Tipos de clima segundo a amplitude de variação do Índice de Aridez (P/ETP) da UNEP (1991).

\begin{tabular}{c|c}
\hline Zonas climáticas & Amplitude do Índice de Aridez (IA) \\
\hline Hiper-árido & $<0,005$ \\
\hline Árido & $0,05-0,20$ \\
\hline Semiárido & $0,21-0,50$ \\
\hline Subúmido seco & $0,51-0,65$ \\
\hline Subúmido e úmido & $>0,65$ \\
\hline
\end{tabular}

Fonte: UNEP (1991).

De acordo com a Convenção das Nações Unidas de Combate à Desertificação, as áreas susceptíveis à desertificação no Brasil (ASD) estão localizadas em sua maioria na Região Nordeste, com predomínio de climas semiáridos e subúmidos secos, e Índice de Aridez variando entre 0,21 a 0,65. Estas terras secas têm em comum 0 fato de serem caracterizadas pela ausência, escassez, quantidade limitada e ainda pela má distribuição das precipitações pluviométricas, associadas a elevadas taxas de evaporação. Aliese a estas características o uso inadequado da terra e das pressões excessivas sobre os recursos naturais nesses ambientes.

$O$ intenso dinamismo dos processos e fatores de ordem natural que atuam na superfície da terra, aliado à totalidade das atividades humanas, especialmente após a Primeira Revolução Industrial, culmina em intensos processos de degradação ambiental, que ensejam diagnósticos precisos e rápidos para sua posterior intervenção e minimização.

$\mathrm{Na}$ atualidade, os Sistemas de Informação Geográfica (SIG), ao que se adita o emprego de imagens orbitais, constituem ferramentas indispensáveis para a detecção, avaliação e monitoramento espaço-temporal dos problemas relacionados ao meio ambiente, em virtude da integração e sobreposição de dados diferentes, em variadas escalas, permitido pelos sistemas de informação geográfica, facilitando a tomada de decisões e reorientações, quando necessárias, de políticas de uso e ocupação do solo.

A utilização da cobertura vegetal como indicador nos estudos ambientais é ratificada pelas afirmativas de Accioly et al.(2002 e 2005), Bertrand (2004), Vasconcelos Sobrinho (1978) e de Vieira (1978). Este último considera que o indicador biológico-agrícola mais importante da desertificação, consiste nas 
modificações sofridas pela cobertura vegetal de plantas perenes durante a estação seca.

Desde a década de 1970 os métodos de levantamento do uso da terra e da evolução da cobertura vegetal passaram a contar com a utilização de técnicas de sensoriamento remoto, que se destacam pelo fato de permitirem o estudo de espaços geográficos de dimensões significativas e de forma temporal.

A ferramenta, Sensoriamento Remoto, é um dos indicadores recomendados pela ONU para avaliar o problema da desertificação. A avaliação da dinâmica da cobertura vegetal é um componente de grande relevância para o equilíbrio ambiental, uma vez que garante a proteção dos solos contra a erosão, condição material para o estabelecimento de processos de desertificação, conforme demonstra a Figura 1.

Barbosa et al.(2009) estudaram a evolução da cobertura vegetal e uso agrícola do solos do município de Lagoa Seca- PB. O estudo baseou-se em fotos aéreas de 1984 e imagens do Landsat TM3, TM4 e TM5 de 1989, aliadas a levantamentos através de sistema de posicionamento global (GPS). Identificaram sete fisionomias diferenciadas de cobertura vegetal e uso agrícola. Consideram que o emprego das tecnologias de SIG é fundamental para o resgate do passado e elaboração de planejamento futuro das paisagens.

Sá et al. (2010) analisaram a cobertura vegetal de parte da região do Araripe Pernambucano com emprego do uso de imagens digitais do sensor Thematic Mapper (TM) do satélite LANDSAT 5, datadas de 21/09/2008. Estabeleceram oito classes de NDVI (Índice de Vegetação por Diferença Normalizada, que indica o vigor da vegetação) e de cobertura vegetal e uso da terra. Afirmam que o mapeamento da cobertura vegetal e uso da terra na região do Araripe pernambucano constitui ferramenta bastante útil para o planejamento do espaço territorial da região da chapada do Araripe.

Silva \& Silva (2011), com o emprego de técnicas de geoprocessamento e sensoriamento remoto combinadas a índices de paisagem, analisaram a cobertura vegetal de Lucena entre os anos de 1970 e 2005. Constataram significativa fragmentação de áreas de mata em detrimento especialmente do 
cultivo de cana-de-açúcar. Em 1970, havia cerca de 2.150 ha de matas na área estudada, enquanto em 2005 esta área era de apenas 769 ha, uma redução segundo os autores de 1.381 ha de área de mata em 35 anos.

Figura 1 - Relação desertificação e erosão dos solos, adaptada de Roxo \& Mourão (1998) e Aquino (2002)

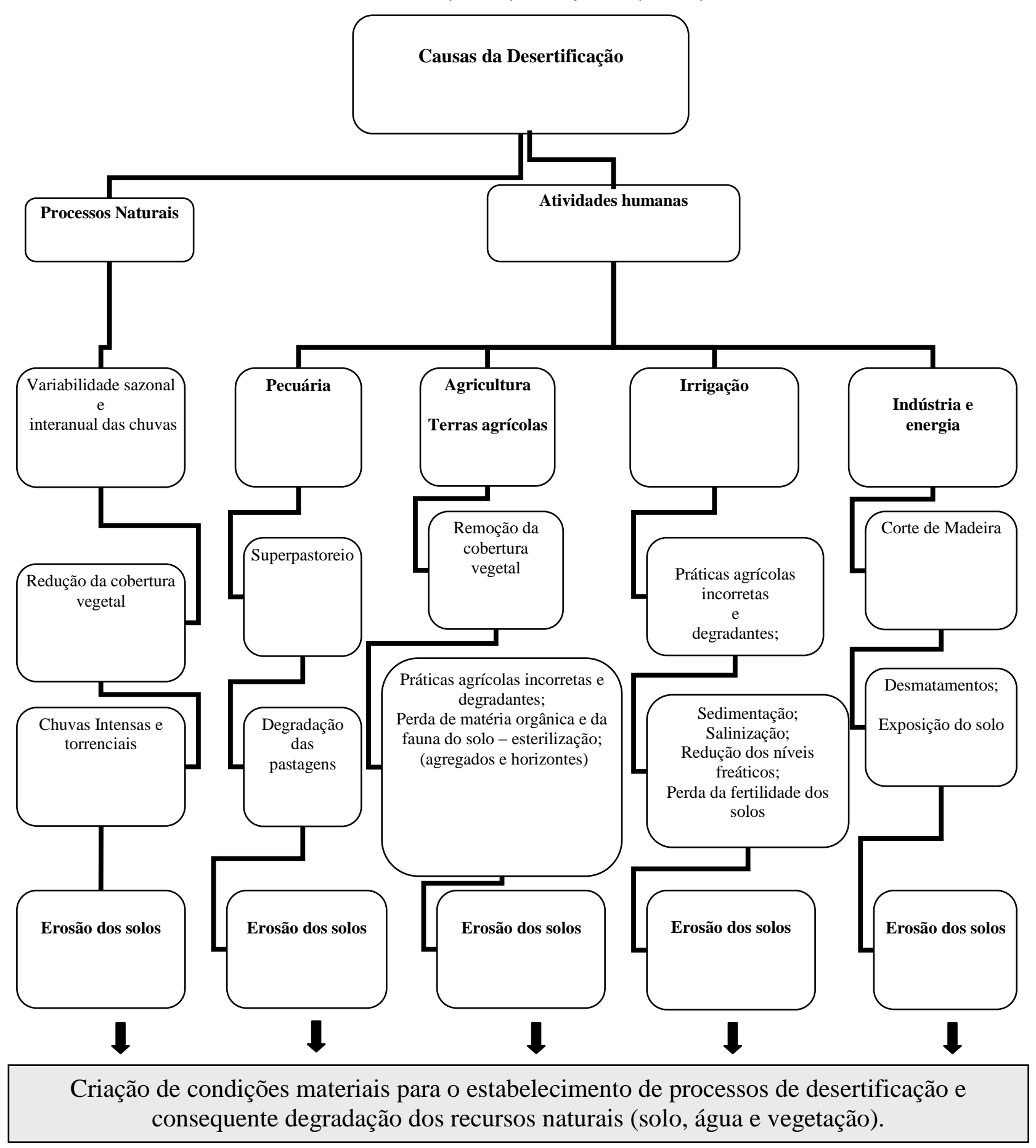

Fonte: Aquino (2010) 
Considerando a afirmação de Brasil (2004), de que o uso e ocupação das terras secas ao longo de várias décadas contribuíram para 0 estabelecimento dos processos de desertificação e determinaram a velocidade de sua ocorrência, objetivou-se neste trabalho: i) identificar e comparar, com uso de técnicas de sensoriamento remoto, a dinâmica entre os tipos de cobertura vegetal/uso da terra no Núcleo de São Raimundo Nonato entre os anos de 1987 e 2007 e ii) estabelecer relações entre os tipos de cobertura vegetal/uso da terra e o NDVI da área de estudo, para fins de analisar a degradação/desertificação no Núcleo de São Raimundo Nonato, área suscetível a desertificação de acordo com Brasil (2004).

\section{Material e métodos}

\section{1. Área de estudo}

A área geográfica de estudo localiza-se na porção sudeste do estado do Piauí, integrando a microrregião de São Raimundo Nonato. Localiza-se entre as coordenadas de $8^{\circ} 57^{\prime} 65^{\prime \prime}$ a $9^{\circ} 59^{\prime} 03^{\prime \prime}$ de latitude Sul e $42^{\circ} 06^{\prime} 44^{\prime \prime}$ a $43^{\circ}$ 03 '25" de longitude oeste, totalizando uma área de aproximadamente 6.988 $\mathrm{km}^{2}$.

O núcleo de São Raimundo Nonato, segundo Aquino (2002), integra área do estado do Piauí suscetível a desertificação e é composto por cinco municípios: São Raimundo Nonato, Coronel José Dias, Bonfim do Piauí, São Lourenço e Dirceu Arcoverde, distribuídos espacialmente conforme Figura 2.

Considerando a geologia regional, o Núcleo de São Raimundo Nonato situa-se em três grandes domínios geológicos: as Províncias São Franciscana, Borborema e Parnaíba. Quanto ao aspecto geomorfológico de acordo com Brasil (1973) a área de estudo exibe duas unidades morfoestruturais i) a superfície tabular estrutural representada por planaltos areníticos cuestiformes e ii) a superfície pediplanada pré-cambriana. 
Figura 2 - Localização da área de estudo e distribuição espacial dos municípios integrantes do Núcleo de São Raimundo Nonato - Piauí.

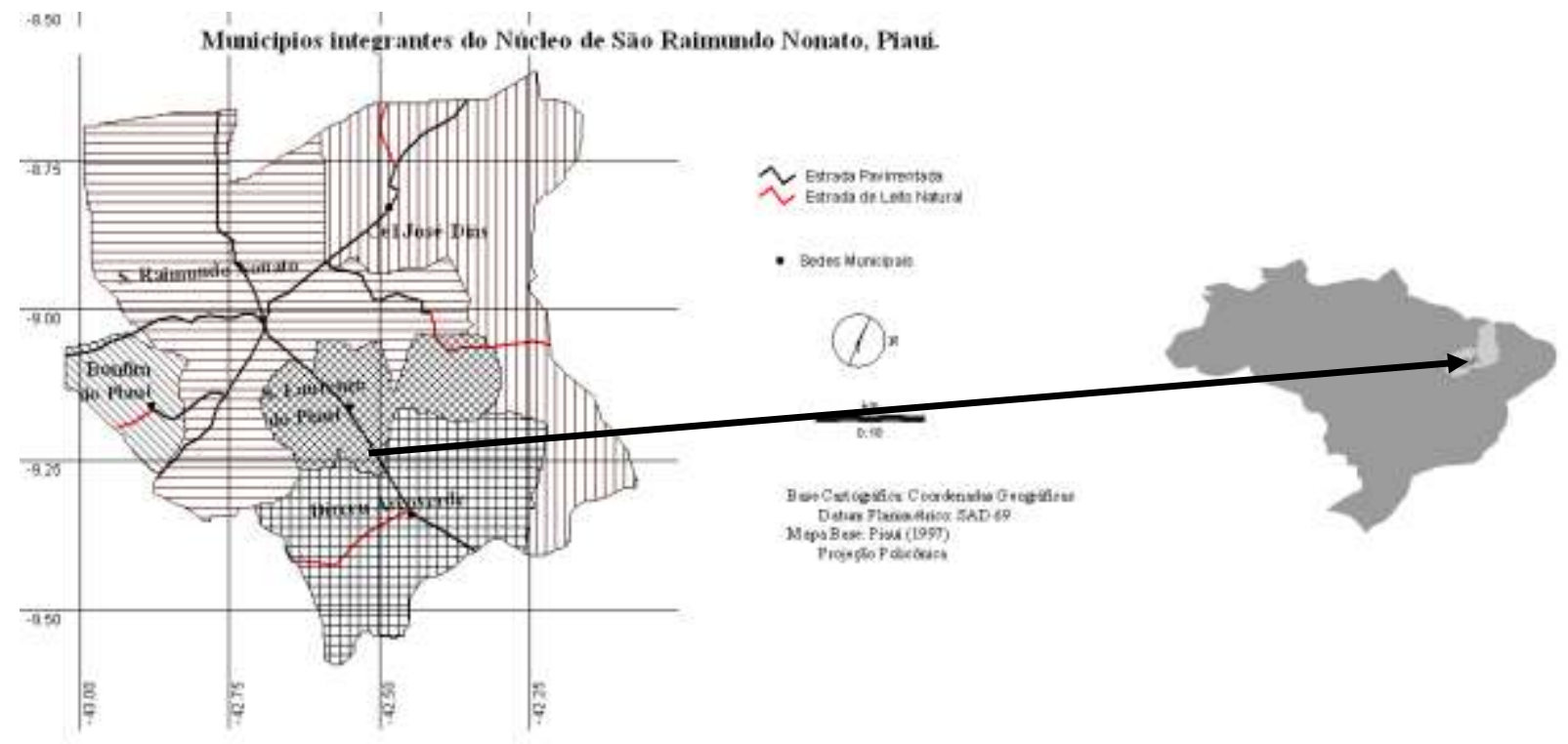

A análise climática da área de estudo baseou-se em dados de precipitação das séries anuais disponíveis em SUDENE (1990), no período compreendido de 1963 a 1985. Foram utilizados 20 postos pluviométricos localizados dentro e no entorno do núcleo de São Raimundo Nonato para análise do balanço hídrico considerando uma série histórica de 23 anos $\mathrm{A}$ análise dos dados revelou valores médios anuais de precipitação variando de $996 \mathrm{~mm}$ a $707 \mathrm{~mm}$.

A evapotranspiração potencial (ETP) da área de estudo, estimada a partir de dados de temperaturas médias mensais obtidas de acordo com Lima et.al (1982), apresenta valores em todos os postos analisados superiores a $1000 \mathrm{~mm}$, com um valor médio de $1.462 \mathrm{~mm}$. Estes elevados valores de ETP resultam em parte das elevadas temperaturas a que está submetida a região Nordeste, considerada por Conti (2003) como faixa privilegiada em relação ao recebimento de radiação solar, da concentração de calor e de excedente energético. 
Uma análise comparativa entre os valores médios de precipitação e evapotranspiração potencial permite inferir o significativo déficit hídrico, superior a 400 mm/ano no Núcleo de São Raimundo Nonato.

O índice de aridez (IA) proposto pelo UNEP (1991) para a identificação das terras secas suscetíveis a desertificação foi aplicado e revelou níveis diferenciados de aridez para a área de estudo com valores de IA variando de < 0,20 a $<0,65$, com predominância de valores entre 0,20 a 0,50, permitindo 0 enquadramento climático da área na tipologia semiárida. Os valores do Índice Efetivo de Umidade (Im) (THORNTHWAITE \& MATHER, 1955) obtidos variaram de -33 a -60 reforçando a ocorrência de um clima semiárido para a área de estudo. O coeficiente de variação do Im oscilou de $28,2 \%$ a 43,9\%, evidenciando assim a fragilidade climática e consequentemente ecológica da área de estudo.

No que concerne à distribuição temporal das precipitações, constata-se que a área de estudo apresenta de oito a onze meses secos. Os gráficos ombrotérmicos apresentados na Figura 3 revelam o comportamento médio das chuvas e das temperaturas nos postos pluviométricos inseridos na área de estudo e reforçam a constatação da concentração das precipitações num curto período do ano.

Nos postos analisados constatam-se poucas oscilações, evidenciando regular distribuição dos valores de temperatura média em todos os meses. $O$ gráfico também permite inferir serem os meses de janeiro, fevereiro e março os mais chuvosos e, portanto, de maior atividade vegetal, e que os meses de junho, julho, agosto e setembro são os mais secos, e caracterizam uma situação ecológica de déficit hídrico nestes períodos.

A variedade litológica, aliada ao condicionante climático favorecem a ocorrência diferenciada de solos Latossolo (61,9\%), Argissolo (17,4\%), Neossolo Litólico (16,7\%), Neossolo Regolítico (3,6\%) e Luvissolo (0,4\%), sobre os quais identifica-se a presença de cobertura vegetal xerofítica, com caducifolia sazonal representada pelas caatingas. 
Figura 3 - Gráficos ombrotérmicos dos postos pluviométricos Bom Jardim e Cavalheiro, localizados no Núcleo de Desertificação de São Raimundo Nonato - PI, no período de 1963 a 1985.
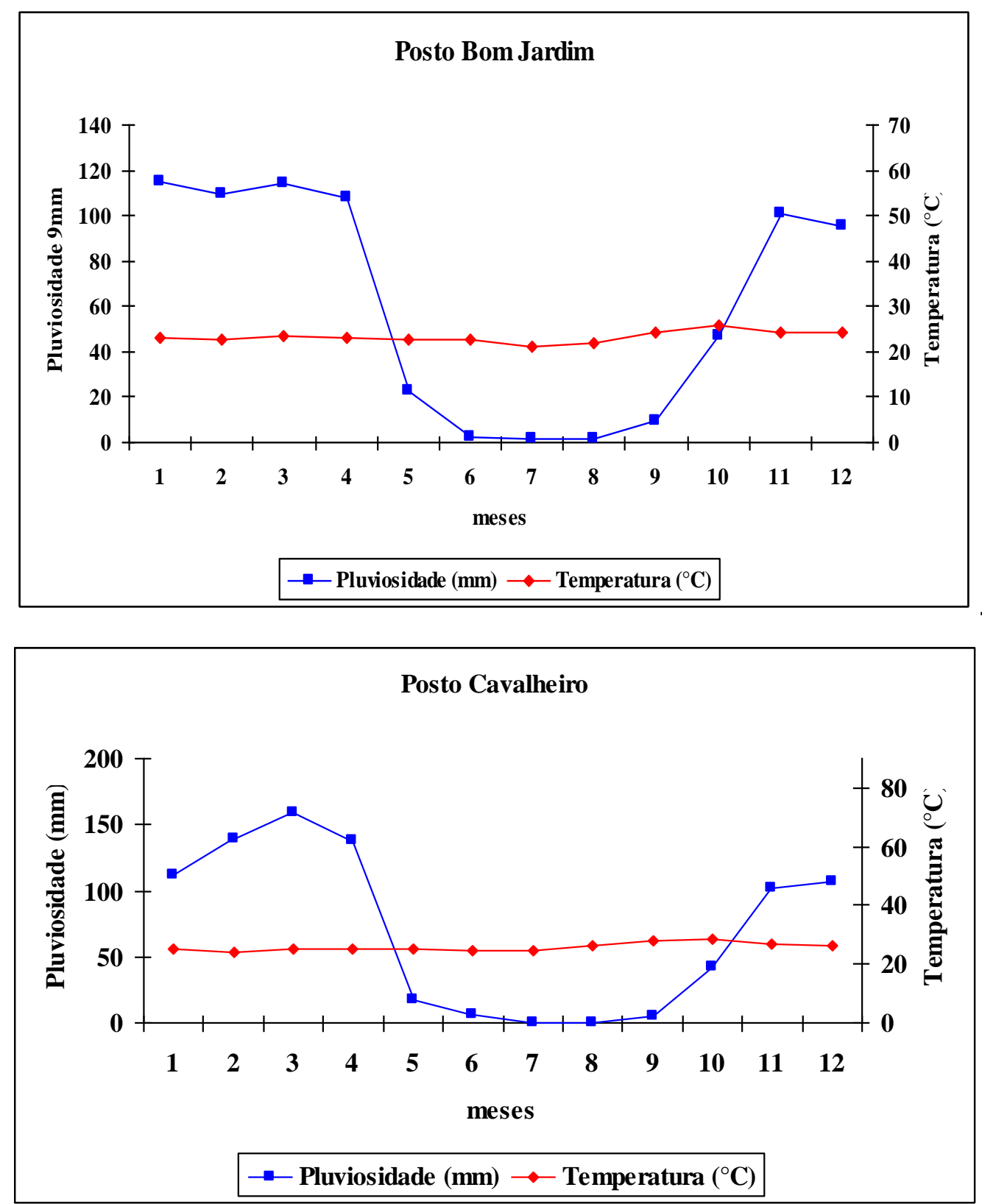

Fonte: Aquino (2010) 


\subsection{Aspectos econômicos e demográficos do núcleo de São Raimundo Nonato}

Na sucessão dos tempos históricos, o Núcleo de São Raimundo Nonato, como o resto do Nordeste brasileiro, teve seu devassamento e povoamento decorrente da expansão da pecuária que teve início no século XVII, com o consequente espalhamento das fazendas de gado para o Hinterland. Aliada à pecuária destaca-se a atividade da agricultura de subsistência, conforme gráfico da Figura 4.

Figura 4 - Porcentagem das classes de atividades econômicas desenvolvidas no Núcleo de São Raimundo Nonato nos anos de 1985 e 1995/1996.

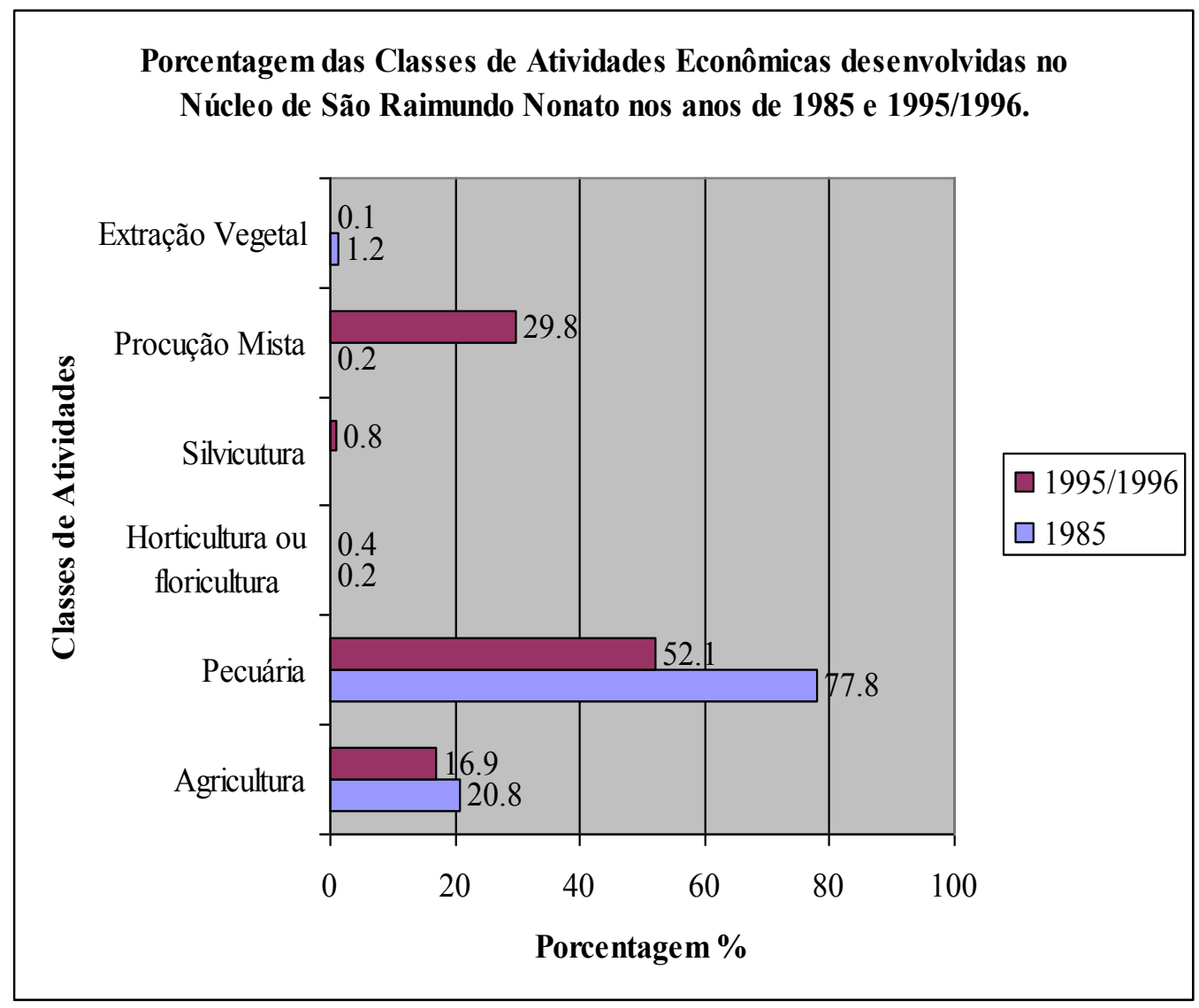


A Figura 5 apresenta a porcentagem dos principais produtos agrícolas do Núcleo de São Raimundo Nonato nos anos de 1989, 1995, 2001 e 2006.

Figura 5 - Porcentagem dos principais produtos agrícolas do Núcleo de São Raimundo Nonato nos anos de 1989, 1995, 2001 e 2006.

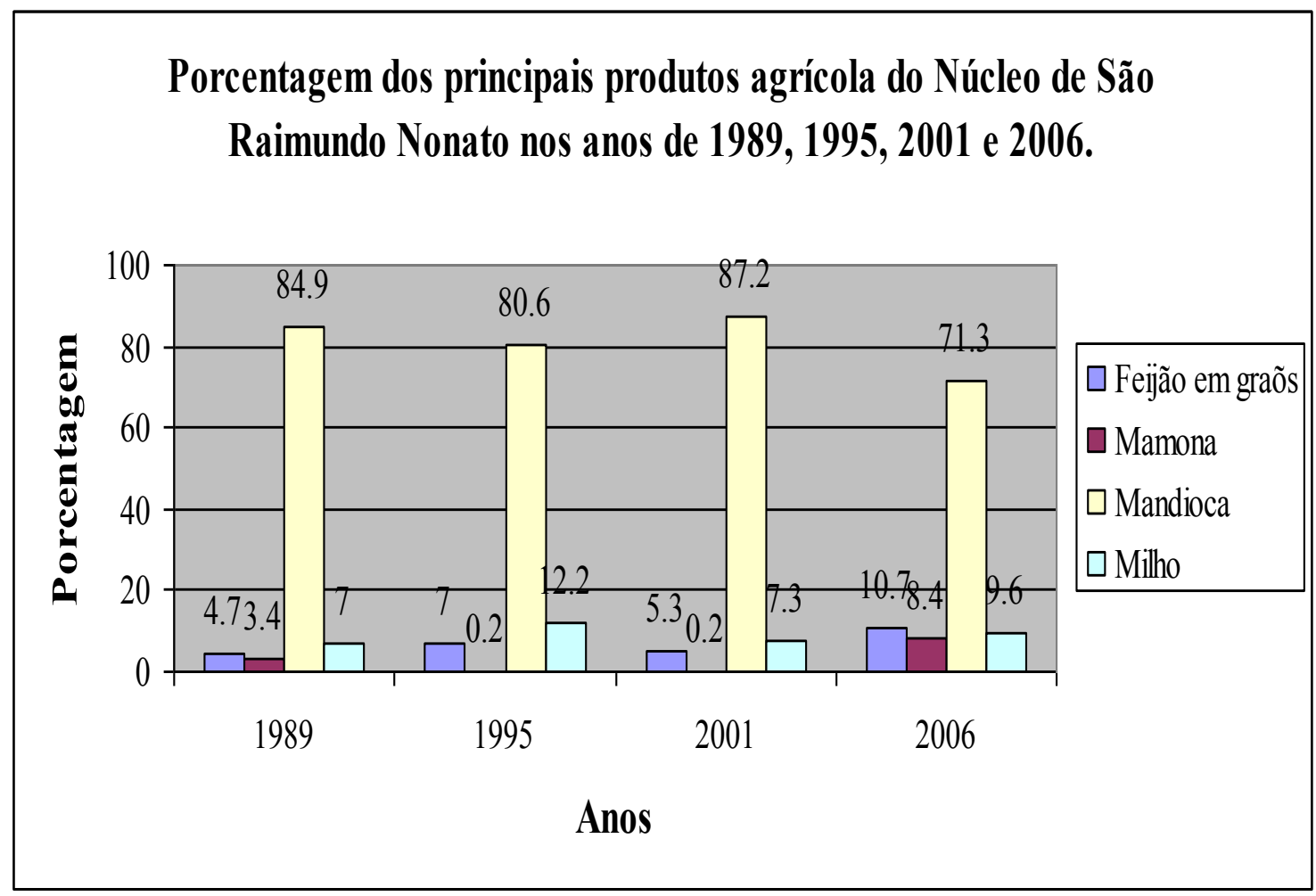

Aquino (2010) afirma que, de modo geral, nos anos de 1989, 1995, 2001 e 2006 constatam-se mudanças significativas (tendência de redução) tanto na área plantada, como nas quantidades produzidas das culturas de subsistência (milho, feijão e mandioca). A redução entre os anos de 1989 e 2006 para o cultivo de milho, feijão e mandioca foi de 95,3\%, 91,8\% e 97\% respectivamente. Esta redução, na opinião da autora, pode resultar dentre outros fatores, da queda progressiva da população rural e do aumento da população urbana, especialmente após o ano de 1993, quando da 
emancipação dos municípios de Bonfim do Piauí, Coronel José Dias e São Lourenço.

A dinâmica populacional na área de estudo entre os anos de 1970, 1980, 1991, 1996 e 2007 é apresentada na figura 6.

Figura 6 - evolução da População urbana no Núcleo de São Raimundo Nonato nos anos de 1970, 1980, 1991, 1996 e 2007.

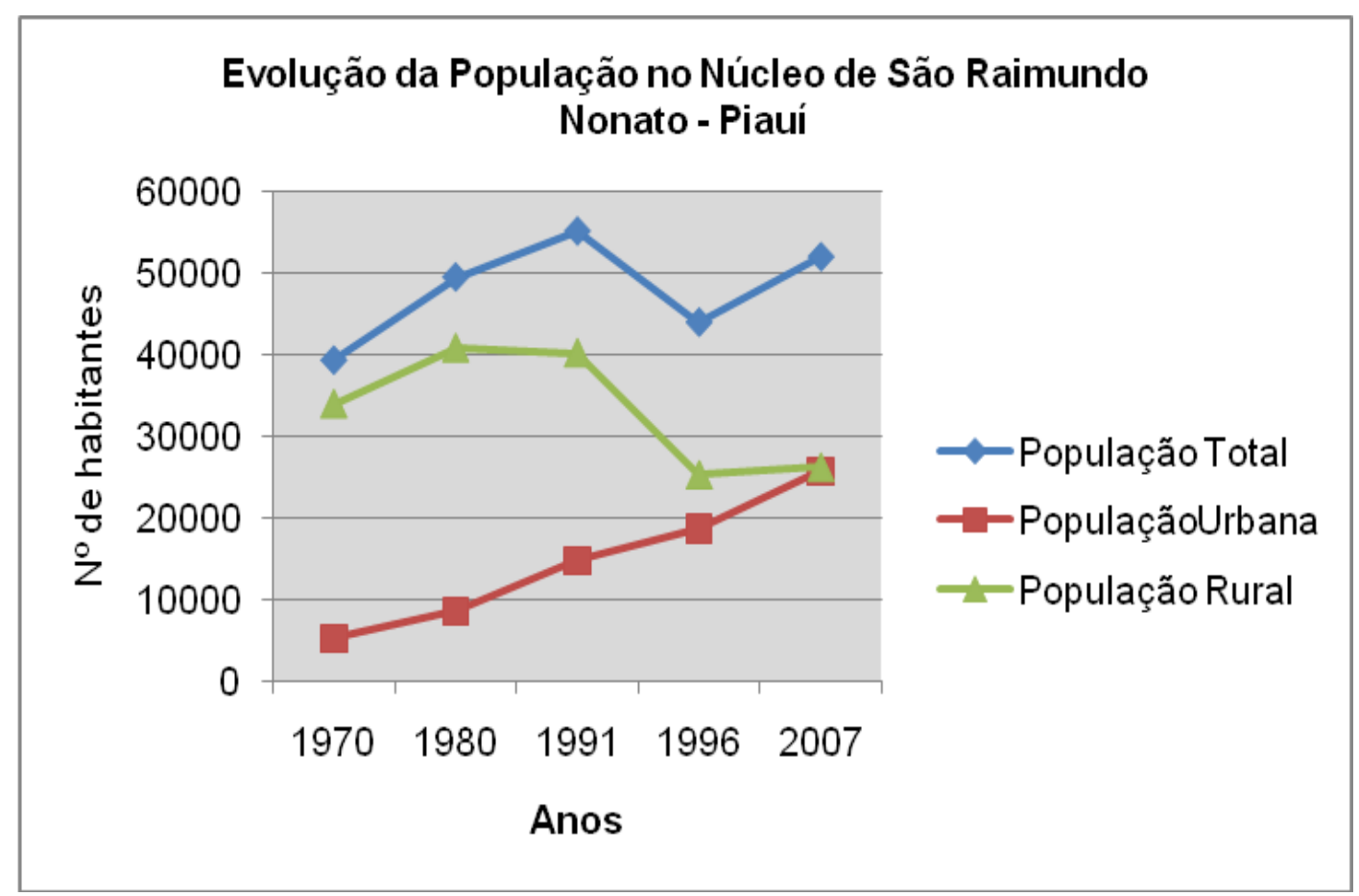

A consolidação da estrutura dos municípios emancipados, o conseqüente aumento da possibilidade de acesso a equipamentos públicos, estão entre os aspectos responsáveis pelo significativo aumento no contingente urbano da área de estudo.

A pecuária extensiva historicamente tem-se constituído a principal atividade econômica no Núcleo de São Raimundo Nonato. No entanto, ao 
longo dos anos esta atividade vem sofrendo algumas modificações que podem ser constatadas a partir dos dados constantes na Figura 7.

Figura 7 - Porcentagem de efetivos bovinos, ovinos e caprinos no Núcleo de São Raimundo Nonato nos anos de 1991, 1995, 2001 e 2006.

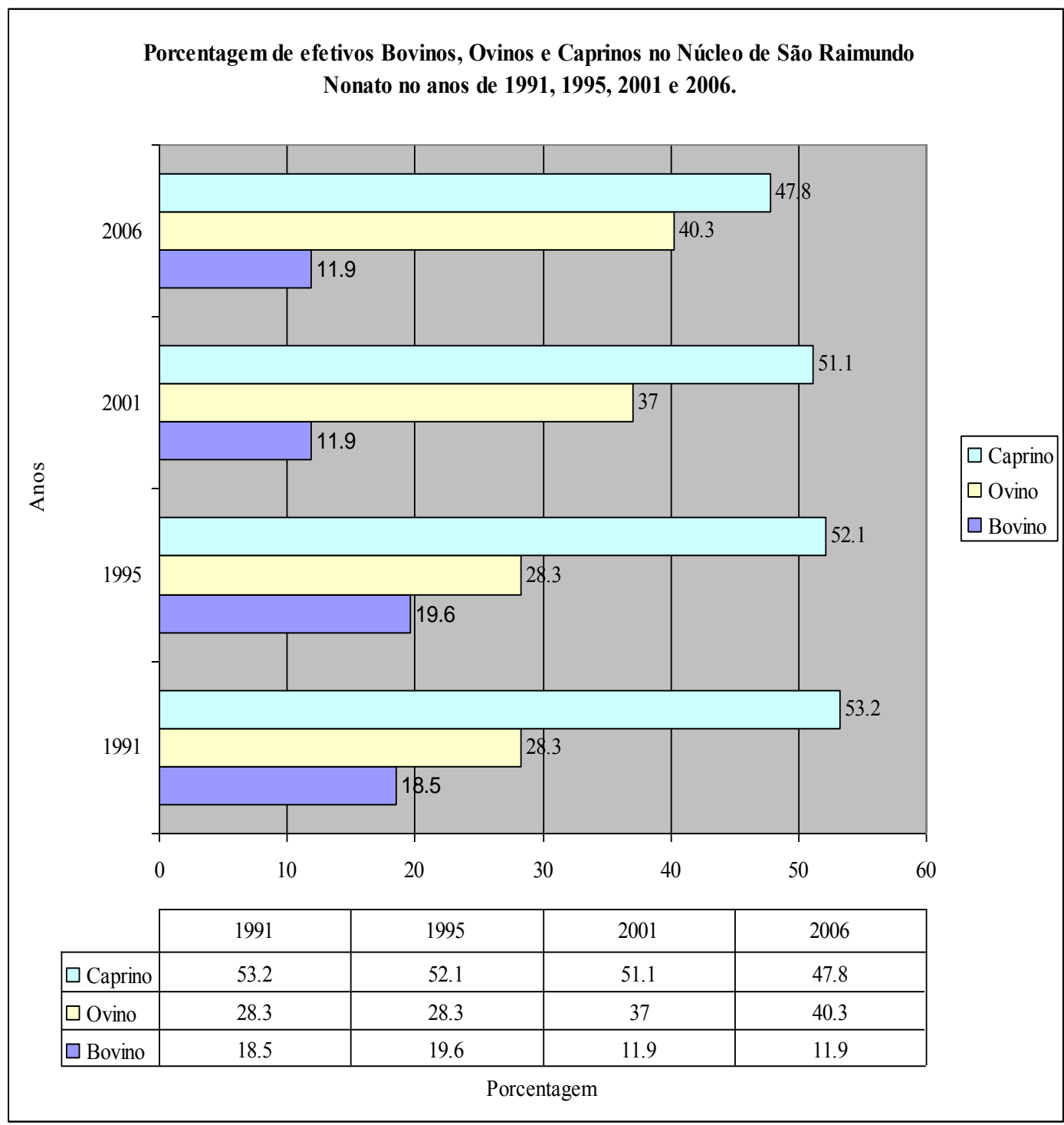




\subsection{Procedimentos metodológicos e técnicos}

O trabalho baseou-se em técnicas de sensoriamento remoto. Por meio destas, são fornecidas imagens de grandes áreas, muitas vezes de acesso difícil, a custo relativamente baixo e com uma certa periodicidade, o que potencializa sua utilização nos levantamentos dos diferentes tipos de cobertura vegetal e uso das terras, bem como nos estudos de degradação ambiental.

Estudos como os de Accioly et al.(2002 e 2005), Campos et. al (2004), Franco et al. (2007), Sousa et. al. (2008), Fernandes et al. (2009), Oliveira et al. (2009), Lopes et al. (2010), Rosemback et al. (2010), Sá et al. (2010) e Melo et al. (2011), constituem referência no emprego de técnicas de sensoriamento remoto para análise da dinâmica da cobertura vegetal e avaliação de áreas degradadas/desertificadas.

Na restituição de padrões de tipos de cobertura vegetal e uso da terra do ano de 1987, foram utilizadas as bandas espectrais 2, 3, 4 e 5, do Landsat 5 TM, considerando a resposta espectral dos alvos, aliada a conhecimentos relativos a clima, solo e relevo da área de estudo conforme sugeridos por Beltrame (1994).

Para o ano de 2007, as análises das imagens foram realizadas com base na composição das bandas espectrais 2, 3, 4 e 5, do Landsat 5 TM combinadas com inspeções de campo. As imagens empregadas com os respectivos pontos, órbitas, datas de passagem do satélite, sensor e resolução estão listadas no Quadro 1. As imagens foram adquiridas gratuitamente do Instituto Nacional de Pesquisas Espaciais (INPE).

As imagens orbitais oriundas do INPE foram importadas para o GIS IDRISI 3.2, em seguida georreferenciadas no sistema de coordenadas geográficas (latitude-longitude) com emprego do método imagem - imagem. Após o registro das imagens com o uso do utilitário Mosaic, as imagens foram mosaicadas, em seguida, com o utilitário Overlay a imagem foi recortada considerando os limites geográficos da área de estudo. 
Quadro1 - Características das imagens LANDSAT com a cobertura de nuvens $<10 \%$ utilizadas para identificação de tipologias de cobertura vegetal e uso da terra no Núcleo de São Raimundo Nonato.

\begin{tabular}{|c|c|c|c|c|c|c|c|}
\hline \multicolumn{4}{|c|}{1987} & \multicolumn{4}{|c|}{2007} \\
\hline $\begin{array}{l}\text { Ponto } \\
\text { /órbita }\end{array}$ & Datas & Sensor & Resolução & $\begin{array}{l}\text { Ponto } \\
\text { /órbita }\end{array}$ & Datas & Sensor & Resolução \\
\hline $219 / 66$ & $\begin{array}{l}09 / 08 / 1987 \\
06 / 06 / 1987 \\
\end{array}$ & $\begin{array}{c}\text { Landsat } \\
5 \text { TM }\end{array}$ & 30 metros & $219 / 66$ & 01/09/2007 & $\begin{array}{c}\text { Landsat } \\
5 \mathrm{TM}\end{array}$ & 30 metros \\
\hline $218 / 66$ & $\begin{array}{l}03 / 09 / 1987 \\
30 / 05 / 1987\end{array}$ & $\begin{array}{l}\text { Landsat } \\
5 \text { TM }\end{array}$ & 30 metros & $218 / 66$ & 29/09/2007 & $\begin{array}{c}\text { Landsat } \\
5 \text { TM }\end{array}$ & 30 metros \\
\hline $218 / 67$ & $\begin{array}{l}\text { 03/09/1987; } \\
30 / 05 / 1987\end{array}$ & $\begin{array}{c}\text { Landsat } \\
5 \text { TM }\end{array}$ & 30 metros & $218 / 67$ & $26 / 09 / 2007$ & $\begin{array}{c}\text { Landsat } \\
5 \text { TM }\end{array}$ & 30 metros \\
\hline
\end{tabular}

O mapeamento da dinâmica da cobertura vegetal e uso do solo foi realizado com emprego do método de Classificação Supervisionada, do tipo pixel a pixel objetivando definir regiões homogêneas. A classificação é dita supervisionada, quando o analista, com base no conhecimento da área ou por inferência, relaciona áreas da imagem com as classes de cobertura da terra que deseja separar (CRÓSTA, 2001).

O enquadramento de um pixel a uma determinada classe é feito por vários métodos, levando-se em consideração os valores de níveis de cinza nas várias bandas utilizadas (neste estudo, utilizaram-se as bandas 2, 3, 4 e 5) .0 método empregado neste estudo para enquadramento dos pixels foi 0 MAKESIG do IDRISI 3.2, associando a cada pixel da imagem uma assinatura similar. Na sequência utilizou-se o módulo MAXLIKE do IDRISI 3.2, com o emprego do método da máxima verossimilhança, para atribuir a cada pixel identificado sua respectiva assinatura espectral, gerando uma imagem classificada.

As fácies de cobertura vegetal foram identificadas por meio de uma chave de interpretação, considerando as variáveis forma, textura, tonalidade, tamanho e localização. 


\section{Resultados}

\subsection{Dinâmica da cobertura vegetal e uso da terra nos anos de 1987 e 2007}

As fácies de cobertura vegetal identificadas, considerando a estratificação (distribuição das plantas conforme suas alturas) e ainda a densidade entre as espécies, foram: caatinga arbórea, caatinga arbustiva densa, caatinga arbustiva aberta e agropecuária + solo exposto. $O$ fato de as áreas utilizadas para agricultura e pecuária na estação seca exibirem, em sua maioria, a presença de solo exposto, identificadas nas imagens como sendo as áreas mais claras, justifica a junção destas duas categorias em uma única classe. A figura 8 apresenta a fisionomia das classes estabelecidas.

A Figura 9 apresenta a distribuição espacial dos tipos de cobertura vegetal e uso das terras para os anos de 1987 e 2007. Com base nesta Figura, constata-se para o ano de 1987 a seguinte distribuição espacial entre as classes: $12,0 \%$ catinga arbórea, 24,9\% caatinga arbustiva densa, 32,0\% caatinga arbustiva aberta e 31,1\% agropecuária + solo exposto. Para o ano de 2007 a distribuição das fácies apresentadas anteriormente e a seguinte: 4,9\%, $39,3 \%, 29,0 \%$ e $26,8 \%$ respectivamente.

A avaliação da detecção de mudanças entre os tipos de cobertura vegetal e uso da terra entre os anos de 1987 e 2007 objetivou identificar e avaliar processos de degradação e/ou recuperação ambiental na área de estudo. A avaliação destas mudanças pode ser constatada na Tabela 2, que apresenta as modificações nos tipos de cobertura vegetal identificados em 1987, com as respectivas alterações sofridas por eles em 2007. 
Figura 8 - Fisionomias da cobertura vegetal na área de estudo.

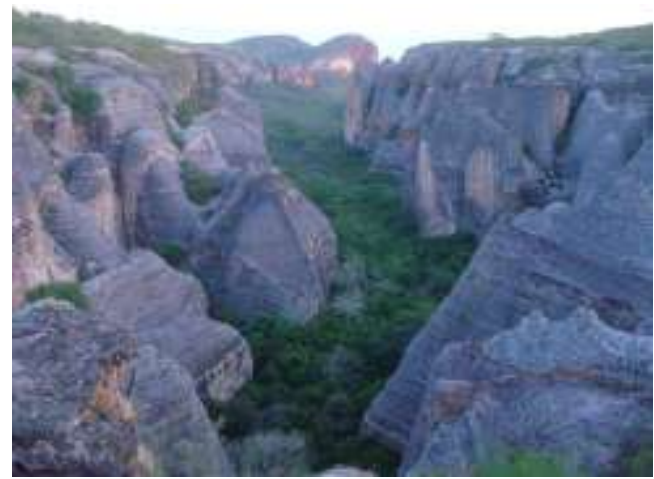

Caatinga arbórea

Fonte: http://www.turismobrasil.gov.br
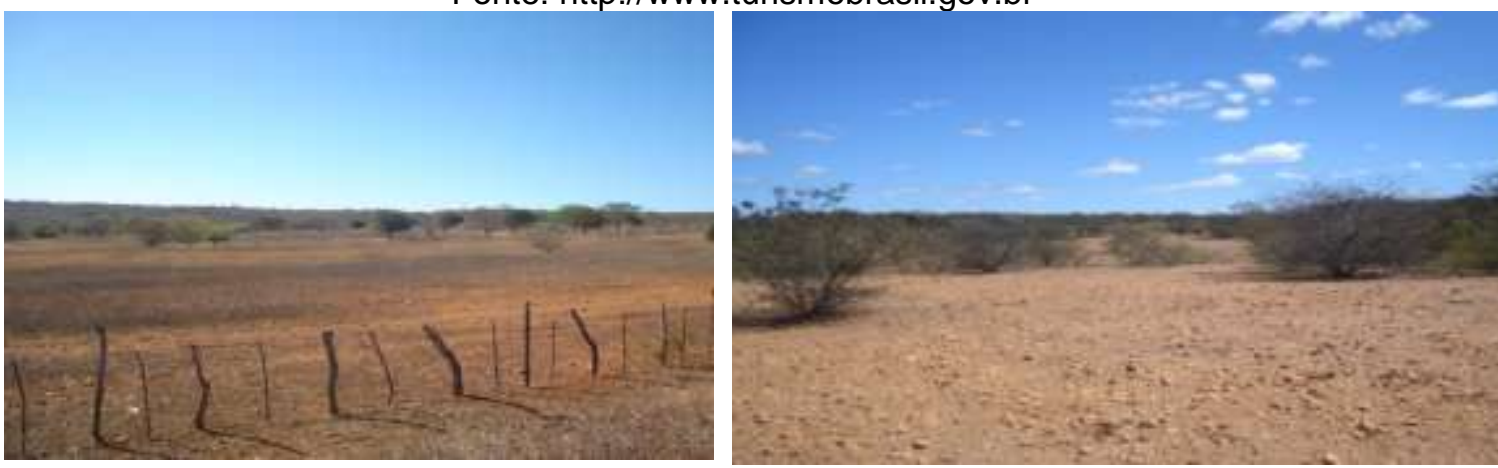

Caatinga arbustiva aberta
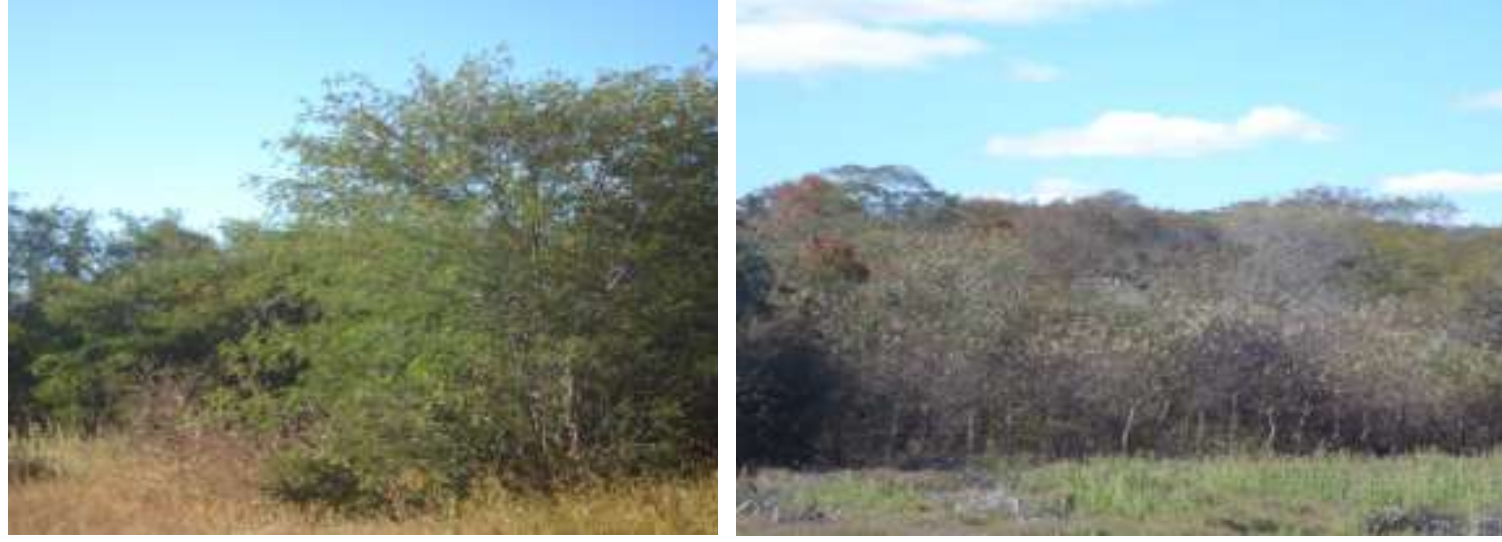

Caatinga arbustiva densa
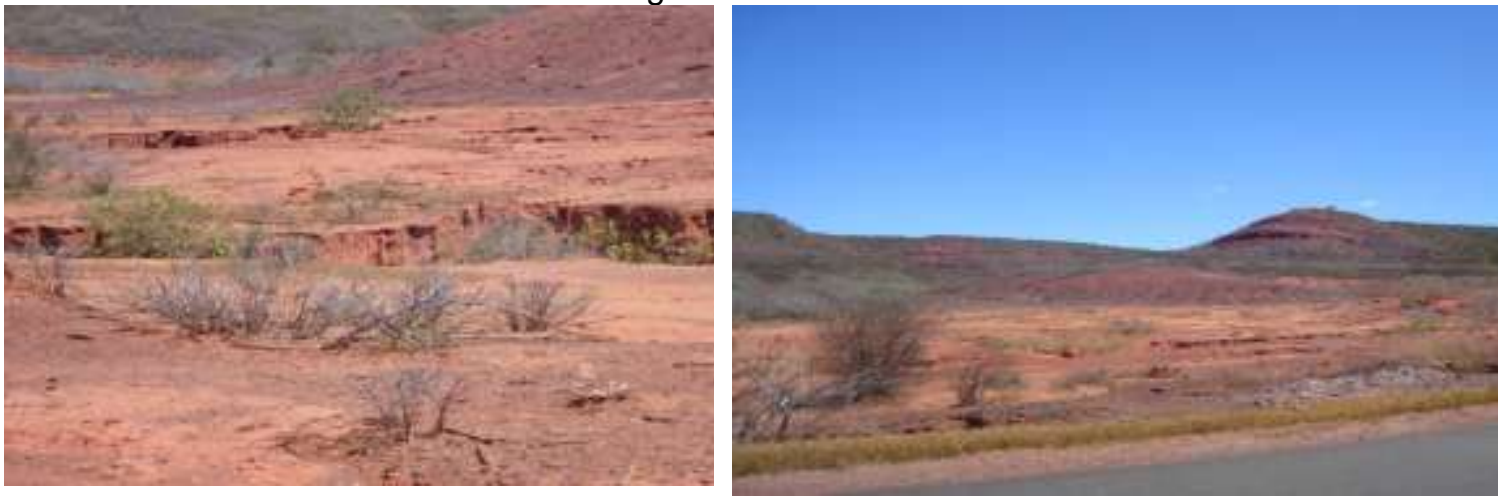

Solo exposto, recoberto por pedregosidade circundada por vegetação arbustiva aberta Fonte: Aquino (2010) 
Figura 9 - Formações Vegetais e Uso da Terra no Núcleo de S. Raimundo Nonato nos anos de 1987 e 2007.

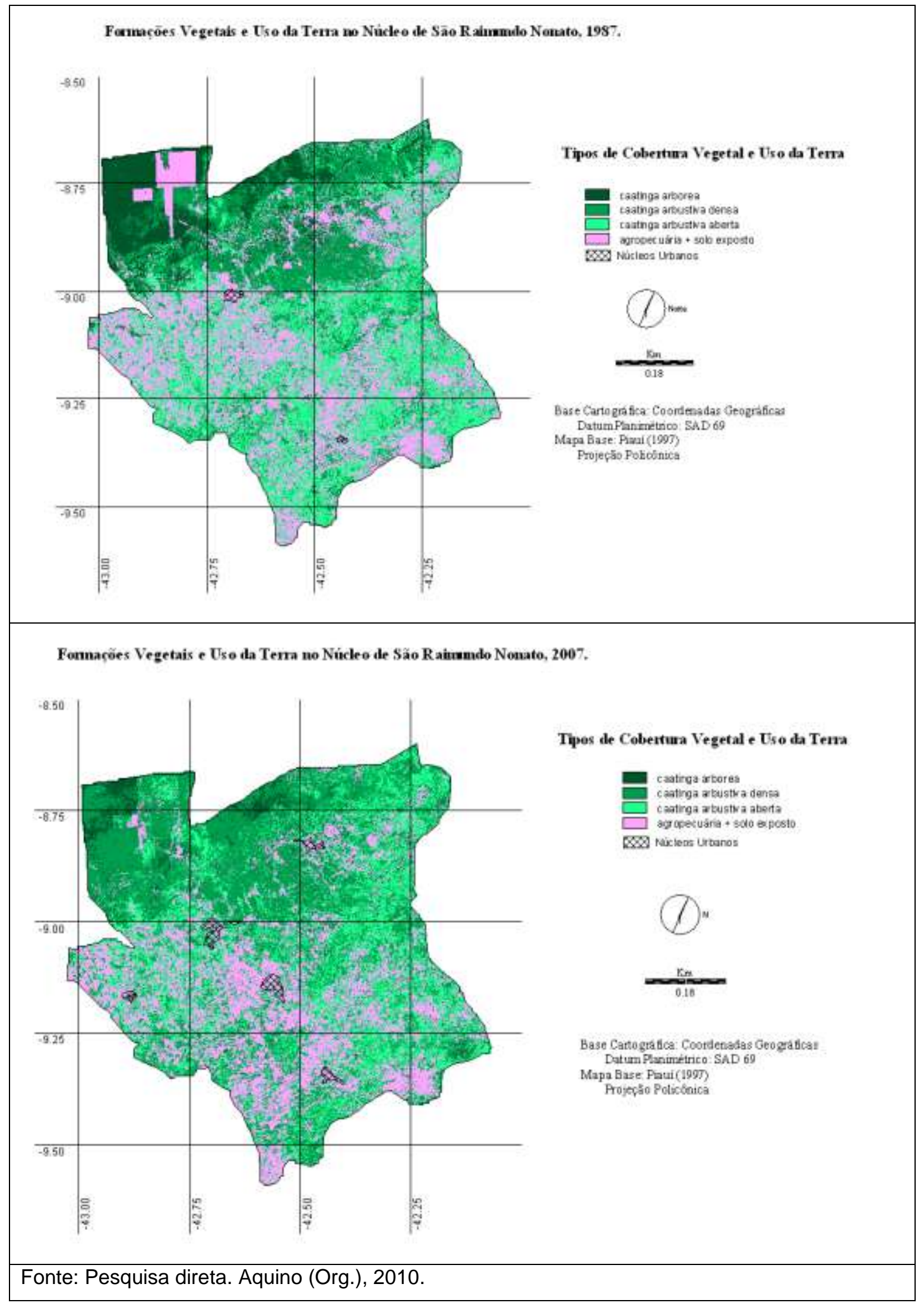


Tabela 2 - Distribuição absoluta e relativa dos tipos de vegetaçãoluso da terra na imagem de 1987 e sua dinâmica na imagem de 2007.

\begin{tabular}{|c|c|c|c|c|c|c|}
\hline \multirow{3}{*}{\multicolumn{3}{|c|}{ Tipos de vege }} & \multicolumn{4}{|c|}{$\begin{array}{l}\text { Dinâmica dos tipos de vegetaçãoluso da terra } \\
\qquad(2007)\end{array}$} \\
\hline & & & \multirow{2}{*}{ Arbórea } & \multirow{2}{*}{$\begin{array}{c}\text { Arbustiva } \\
\text { Densa }\end{array}$} & \multirow{2}{*}{$\begin{array}{c}\text { Arbustiva } \\
\text { Aberta }\end{array}$} & \multirow{2}{*}{$\begin{array}{c}\text { Agropecuária } \\
\text { +solos } \\
\text { exposto }\end{array}$} \\
\hline & & & & & & \\
\hline \multirow[t]{2}{*}{ Arbórea } & $\begin{array}{l}\text { Área } \\
\left(\mathrm{Km}^{2}\right)\end{array}$ & 835,7 & 147,3 & 546,8 & 93,6 & 48,0 \\
\hline & $\%$ & 12,0 & 17,7 & 65,4 & 11,2 & 5,7 \\
\hline \multirow[t]{2}{*}{$\begin{array}{c}\text { Arbustiva } \\
\text { Densa }\end{array}$} & $\begin{array}{l}\text { Área } \\
\left(\mathrm{Km}^{2}\right)\end{array}$ & 1741,2 & 60,7 & 1035,7 & 431,1 & 213,7 \\
\hline & $\%$ & 24,9 & 3,5 & 59,5 & 24,8 & 12,2 \\
\hline \multirow[t]{2}{*}{$\begin{array}{c}\text { Arbustiva } \\
\text { Aberta }\end{array}$} & $\begin{array}{l}\text { Área } \\
\left(\mathrm{Km}^{2}\right)\end{array}$ & 2235,6 & 64,6 & 701,0 & 903,0 & 567,0 \\
\hline & $\%$ & 32,0 & 2,9 & 31,4 & 40,4 & 25,3 \\
\hline \multirow{2}{*}{$\begin{array}{c}\text { Agropecuária } \\
+ \\
\text { Solo exposto }\end{array}$} & $\begin{array}{l}\text { Área } \\
\left(\mathrm{Km}^{2}\right)\end{array}$ & 2175,2 & 70,8 & 463,4 & 596,8 & 1044,2 \\
\hline & $\%$ & 31,1 & 3,3 & 21,3 & 27,4 & 48,0 \\
\hline \multirow{2}{*}{$\begin{array}{c}\text { Vegetação } \\
\text { no ano de } \\
2007\end{array}$} & $\begin{array}{l}\text { Área } \\
\left(\mathrm{Km}^{2}\right)\end{array}$ & 6887,7 & 343,4 & 2746,9 & 2024,5 & 1872,9 \\
\hline & $\%$ & 100,0 & 4,9 & 39,3 & 29,0 & 26,8 \\
\hline
\end{tabular}

Fonte: Pesquisa direta. Aquino (Org.), 2009.

Uma análise dos dados constantes na Tabela 2 permite inferir que:

- do total de $835,7 \mathrm{~km}^{2}$, que representava a mancha de caatinga arbórea identificada em 1987, apenas 17,7\% permaneceram nesta classe em 2007 , pois $65,4 \%, 11,2 \%$ e $5,7 \%$ passaram para as classes de caatinga arbustiva densa, caatinga arbustiva aberta e agropecuária + solo exposto, evidenciando assim, desequilíbrios/degradação que podem resultar de variações nas condições climáticas da área e/ou de desmatamentos;

- para o tipo identificado em 1987 como caatinga arbustiva densa, constatou-se uma recuperação vegetacional em 3,5\% da área que passou em 2007 à categoria de caatinga arbórea, 59,5\% da área mantiveram-se recobertos por caatinga arbustiva densa, 24,8\% e 12,2\% 
passaram para as classes de caatinga arbustiva aberta e agropecuária + solo exposto;

- na classe caatinga arbustiva aberta também podem ser evidenciadas modificações substanciais no sentido de recuperação vegetacional, pois em 2,9\% e 31,4\% da área desta mancha a vegetação passou em 2007 para as classes de arbórea e arbustiva densa respectivamente evidenciando assim a ocorrência de sucessão ecológica. Os dados obtidos revelam que $40,4 \%$ desta classe mantiveram-se como caatinga arbustiva aberta e 25,4\%, passaram à categoria agropecuária + solo exposto, indicando aumento de degradação/desertificação;

- mudanças substanciais também foram observadas na categoria agropecuária + solo exposto. Em 2007 apenas 48,0\% da área mapeada permaneceu nesta classe. Foram evidenciadas sucessões ecológicas, sendo que em $3,3 \%, 21,3 \%$ e $27,4 \%$ do que fora mapeado como solo exposto em 1987, em 2007 identificou-se cobertura vegetal do tipo: caatinga arbórea, caatinga arbustiva densa e caatinga arbustiva aberta, o que permite inferir diferentes estádios de sucessão ecológica secundária, com consequente melhoria na dinâmica do ambiente;

- existe aumento no número de núcleos urbanos, já que em 1987 foram mapeados apenas os municípios de São Raimundo Nonato e de Dirceu Arcoverde estes criados em 1961 e 1983 respectivamente. Em 2007, foram a emancipados destes dois Municípios os de Bonfim do Piauí, Coronel José Dias e São Lourenço no ano de 1993, que passaram a constar no mapeamento.

O gráfico da Figura 10 permite visualizar a distribuição dos tipos de cobertura vegetal e uso da terra nos anos estudados e a consequente melhoria na proteção oferecida pela vegetação. 
Figura 10 - Percentuais dos tipos de Cobertura Vegetal e Uso do Solo em 1987 e 2007.

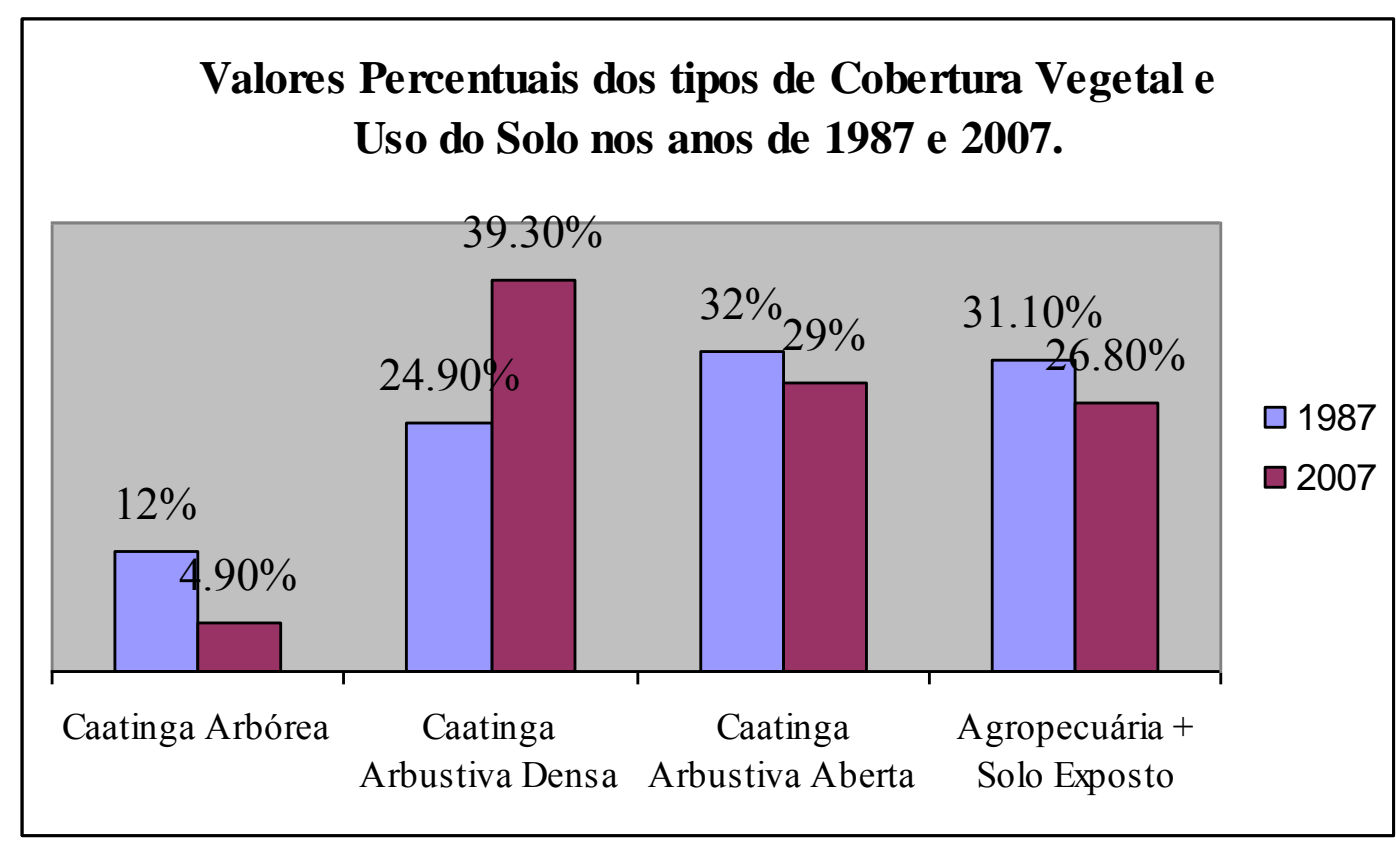

Fonte: Pesquisa direta. Aquino (Org.), 2010.

Constata-se uma coerência nos dados obtidos na pesquisa com os encontrados por Lemos (2003). Esse autor, baseado no porte (altura e diâmetro), caracterizou um hectare de caatinga do Parque Nacional Serra da Capivara. Concluiu que dos 5.827 indivíduos amostrados (73,6\%) do total apresentavam de 2,1 a 5,0 metros e apenas 22 indivíduos $(0,37)$ ultrapassaram 8,0 metros de altura e 26,03\% registraram altura media de 3,5 metros. Estes dados confirmam o predomínio de uma caatinga com fisionomia arbustiva com indivíduos bastante ramificados na área de estudo e a presença de algumas árvores emergentes esparsas. Freitas (2007) afirma ser o predomínio de estratos arbustivos um sinal de possível sucessão secundária na área de estudo.

De acordo com os dados da Tabela anterior, pode-se afirmar que, de modo geral, houve melhoria nos níveis de proteção vegetal na área de estudo entre os anos analisados. Analises de Regressão realizadas entre as imagens, indicou que a proteção da cobertura vegetal, que em 1987 era de 15,7\%, passou para $17,5 \%$ em 2007. 


\section{Conclusões}

- Confirma-se a importância do emprego de técnicas de sensoriamento remoto na avaliação espaço-temporal de mudanças de cobertura vegetal e uso da terra, para fins de analises da degradação ambiental, contudo, entende-se a necessidade de emprego de indicadores complementares a exemplo do NDVI.

- A metodologia adotada mostrou-se eficiente, pois a utilização de imagens orbitais LANDSAT-5, combinadas com técnicas de geoprocessamento, e inspeções a campo evidenciaram resultados bastante confiáveis.

- Os resultados mostraram que houve decréscimo da vegetação de porte arbóreo entre os anos analisados de $12 \%$ para $4,9 \%$. Houve redução significativa da classe de cobertura vegetal/uso da terra do tipo agricultura+solo exposto, esta decresceu de $31,1 \%$ em 1987 para 26,8\% em 2007, já na classe caatinga arbustiva densa constatou-se incremento de $24,9 \%$ para $39,3 \%$.

- As mudanças constatadas nas análises das imagens orbitais entre os anos de 1987 e 2007 no Núcleo de São Raimundo Nonato revelam de modo geral melhora em termos de proteção oferecida pela cobertura vegetal, resultado da ocorrência de uma possível sucessão ecológica secundária, que refletir-se-á em melhoras na condição ambiental, com decréscimos da degradação/desertificação na área de estudo.

- Uma breve avaliação temporal de aspectos econômicos indicou redução nos cultivos temporários de subsistência e nos rebanhos (bovino, ovino e caprino), fatores estes possivelmente responsáveis pelas mudanças nas classes de cobertura vegetal.

- Este resultado enseja a realização de novas pesquisas, que expliquem empiricamente as causas do aumento da cobertura vegetal na área de estudo.

- A carência de estudos para o estado do Piauí, nesta perspectiva, mesmo que em caráter exploratório, deve ser considerado elemento norteador de novas pesquisas. 


\section{Referências Bibliográficas}

ACCIOLY, L.J.O.; PACHECO, A.; COSTA, T.C.C.; LOPES, O.F.; \& OLIVEIRA, M.A.J. Relações empíricas entre a estrutura da vegetação e dados do sensor TM/LANDSAT. Revista Brasileira de Engenharia Agrícola e Ambiental, Campina Grande, v. 6, no 3, p. 492-498, 2002.

ACCIOLY, L.J.O.; GARCON, E.A.M.; BARROS, M.R.O.; \& BOTELHO, F. Avaliação de alvos em áreas sob desertificação no semiárido paraibano com base nos sensores Hyperion e LANDSAT7 ETM+. In: Anais XII Simpósio Brasileiro de Sensoriamento Remoto, Goiânia, p. 347-353, Abril, 2005.

AQUINO, C. M. S. Suscetibilidade Geoambiental das Terras Secas do Estado do Piauí à Desertificação. Dissertação de Mestrado - Programa Regional de Pós-Graduação em Desenvolvimento e Meio Ambiente, Universidade Federal do Ceará, Fortaleza, 2002.

AQUINO, C. M. S. Estudo da degradação/desertificação no Núcleo de São Raimundo Nonato - Piauí. Tese (Doutorado em Geografia) - Núcleo de PósGraduação em Geografia, Pró-Reitoria de Pós-Graduação e Pesquisa, Universidade Federal de Sergipe, 2010.

BARBOSA, I; S.; ANDRADE. L. A.; \& ALMEIDA, J. A. P. Evolução da cobertura vegetal e uso agrícola do solo no município de Lagoa Seca, PB. Revista Brasileira de Engenharia Agrícola e Ambiental. Campina Grande, v.13, ํㅡ 5, p. 614-622, 2009.

BELTRAME, A.V. Diagnóstico do meio físico de bacias hidrográficas: modelo e aplicação. Florianópolis: Ed. da UFSC, 1994.

BERTRAND, G. Paisagem e Geografia Física global: esboço metodológico. RA'EGA, Curitiba, no 8, p. 141 - 152, 2004.

BRASIL. Departamento Nacional de Produção Mineral. Projeto Radam. Levantamento de Recursos Naturais: Parte das Folhas SC.23 - Rio São Francisco e SC.24 Aracaju. Rio de Janeiro, Vol.1, 1973.

BRASIL. Ministério do Meio Ambiente. Convenção das Nações Unidas de Combate à Desertificação nos Países afetados por seca grave e/ou desertificação, particularmente na África - CCD. Brasília: MMA, 1996. 89p.

BRASIL. Ministério do Meio Ambiente. Programa de ação Nacional de Combate à desertificação e Mitigação dos Efeitos da Seca, PAN-BRASIL. Edição comemorativa dos 10 anos da Convenção das Nações Unidas de Combate à Desertificação e Mitigação dos Efeitos da Seca - CCD. Brasília: MMA, 2004. 225p.

CAMPOS, S.; SILVA, M.; PIROLI, E. L.; CARDOSO, L.G. BARROS, Z.X. Evolução do uso da terra entre 1996 e 1999 no município de Botucatu - SP. Engenharia Agrícola, Jabotiocabal, vol. 24, № 1, p. 211-218, jan/abr. 2004. 
CRÓSTA, A.P. Processamento digital de imagens de sensoriamento remoto. Campinas: UNICAMP, $2001.170 \mathrm{p}$.

CONTI, J.B.. A desertificação como forma de degradação ambiental no Brasil. In: RIBEIRO, W.C. (org.). Patrimônio Ambiental Brasileiro. São Paulo: EDUSP, 2003.

FERNANDES, L. R.; ALMEIDA, A.M.; DUARTE, C. R. Evolução da "cobertura vegetal"no município de Carnaúba dos Dantas - região do Seridó/RN. In: Simpósio Brasileiro de Sensoriamento Remoto, XIV, 2009, Natal, 25-30 de abril, p.2721-2728.

FRANCO, E.S.; LIRA, V. M.; FARIAS, M. S.S.; PORDEUS, R.V.; LIMA, V.L.A. Uso de imagens $T M / L a n d s a t ~-~ 5$ na identificação da degradação ambiental na microbacia hidrográfica em Boqueirão - PB. In: Campo-território: revista de geografia agrária, vol. 2, № 3, p. 79-88, fev., 2007.

FREITAS, M.W.D.de. Estudo integrado da paisagem no sertão pernambucano (NE-Brasil) com o uso de sistemas de informação geográfica e sensoriamento remoto. 2007. Dissertação (Mestrado em sensoriamento remoto) - INPE, São José dos Campos, 2007.

LEMOS, J. R. Fitofisionomia de um hectare de caatinga no Parque Nacional Serra da Capivara, Estado do Piauí, Brasil. In: Brasil Florestal, Brasília, ํo 75, 2003.

LIMA, M.G., ALENCAR, P.A.M., e COELHO,H. Normais de temperaturas máxima, mínima e média estimadas em função de latitude, longitude e altitude para o estado do Piauí. Ensaios - Boletim de Pesquisa, 1(1): 1-40, 1982.

LOPES, H.;CANDEIAS, A.L.B.; ACCIOLY, L.J.O.; SOBRAL, M. do C.M. \& PACHECO, A.P. Parâmetros biofísicos na detecção de mudanças na cobertura e uso do solo e,m bacias hidrográficas. In: Revista Brasileira de Engenharia Agrícola e Ambiental, v.14, n.11, p.1210-1219, 2010a.

MMA. Programa de ação Nacional de Combate à desertificação. Disponível em: <http://desertificacao.cnrh-srh.gov.br/>. Acesso em 12 de novembro de 2008.

MELO, E. T.; SALES, M.C.L.; OLIVEIRA, J.G.B. Aplicação do Índice de Vegetação por Diferença Normalizada (NDVI) para análise da degradação ambiental da microbacia hidrográfica do Riacho dos Cavalos, Crateús-CE.In: RA'EGA, Curitiba, vol.23, p. 520-533, 2011.

OLIVEIRA, T. H.; SILVA, J.S.; SILVA, C.A.V.; SANTIAGO, M.M.; MENEZES, J.B.;SILVA, H.A. \& PIMENTEL, R. M. M. Avaliação da Cobertura Vegetal e do Albedo da Bacia Hidrográfica do Rio Moxotó com Imagens do Satélite Landsat 5. In: Anais XIV Simpósio Brasileiro de Sensoriamento Remoto, Natal, Brasil, 25-30 abril 2009. 
RHODES, J. G. Repensando a desertificação: o que sabemos e o que temos aprendido?. Fortaleza: ICID, 1992.

ROXO,M.J. \& J.M.MOURÃO. Um passo contra o deserto: a percepção do fenômeno. Revista Florestal, Lisboa, XI(1):30+34, 1998.

ROSEMBACK, R.; FERREIRA, N.J.; SHIMABUKURO, Y.E.; CONFORTE, J.C. Análise da dinâmica da cobertura vegetal na região sul do Brasil a partir de dados MODIS/TERRA. In: Revista Brasileira de Cartografia, № 62, Edição Especial 2, p.401-416, 2010.

SÁ, I. I. S.; GALVÍNCIO, J. D.; MOURA, M.S.B.; \& SÁ, I.B. Cobertura vegetal e uso da terra na região Araripe pernambucana. Mercator, Fortaleza, v.9, ํo 19, mai./ago., 2010.

SANTOS, P.; NEGRI, A. J. A comparasion of the normalized difference vegetation index and rainfall for the Amazon and northeastern Brazil. Journal of applied meteorology, Washington, v. 36, n 7, p. 958-965, 1997.

SILVA, V.C.L. \& SILVA R. M. Análise da cobertura vegetal em Lucena entre 1970/2005 usando ecologia da paisagem, Sig e sensoriamento remoto. Caminhos de Geografia, Uberlândia, № 12, ํo 37, p 8-20, 2011.

SOUSA, R. F.; BARBOSA, M. P.; SOUSA JÚNIOR, S.P.; NERY, A.P ; LIMA, A.N. Estudo da evolução espaço-temporal da cobertura vegetal do município de Boa Vista - PB, utilizando geoprocessamento. In: Caatinga, Mossoró, vol. 21, no 3, p.22-30. Jun/agos. 2008.

SUDENE. Dados Pluviométricos Mensais do Nordeste: Estado do Piauí. Recife, 1990.

THORNTHWAITE, C.W \& J.R. MATHER. The Water Balance - Publications in Climatology. N. Jersey: Centerton, v. VIII, № 1, 1955.

UNEP. Status of desertification and implementation of the United Nations Plan of Action to Combat Desertification. Nairóbi, 1991.

VASCONCELOS SOBRINHO, J. Metodologia para Identificação de Processos de Desertificação: Manual de Indicadores. Recife: SUDENE, 1978.

VIEIRA, N.M. Estudo geomorfológico das voçorocas de Franca - SP. 1978. 225 f. Tese (Doutorado em História) - Instituto de História e Serviço Social, Universidade Estadual Paulista, Franca, 1978. 